\title{
ASO Visual Abstract: Disparities in Breast-Conserving Therapy for Non-Hispanic American Indian/Alaska Native Women Compared with Non-Hispanic White Women
}

\author{
Jennifer Erdrich, MD MPH FACS ${ }^{1}$, Felina Cordova-Marks, DrPH MPH ${ }^{2}$, Angela R. Monetathchi, BA ${ }^{3}$, \\ Manxia Wu, MD MPH${ }^{4}$, Arica White, $\mathrm{PhD}^{4}$, and Stephanie Melkonian, $\mathrm{PhD}^{5}$ \\ ${ }^{1}$ Division of Surgical Oncology, Department of Surgery, College of Medicine, University of Arizona, Tucson, AZ; \\ ${ }^{2}$ Department of Health Promotion Sciences, College of Public Health, University of Arizona, Tucson, AZ; ${ }^{3}$ University of \\ Arizona, Tucson, AZ; ${ }^{4}$ Division of Cancer Prevention and Control, Centers for Disease Control and Prevention, Atlanta, \\ GA; ${ }^{5}$ Division of Cancer Prevention and Control, Centers for Disease Control and Prevention, Albuquerque, NM
}

American Indian/Alaska Native women have significantly higher percentage of mastectomy and lower percentage of lumpectomy for early-stage breast cancer compared with White women. There were no significant differences in operations for late-stage disease, and no differences in radiation (https://doi.org/10.1245/s10434-02 1-10730-7).

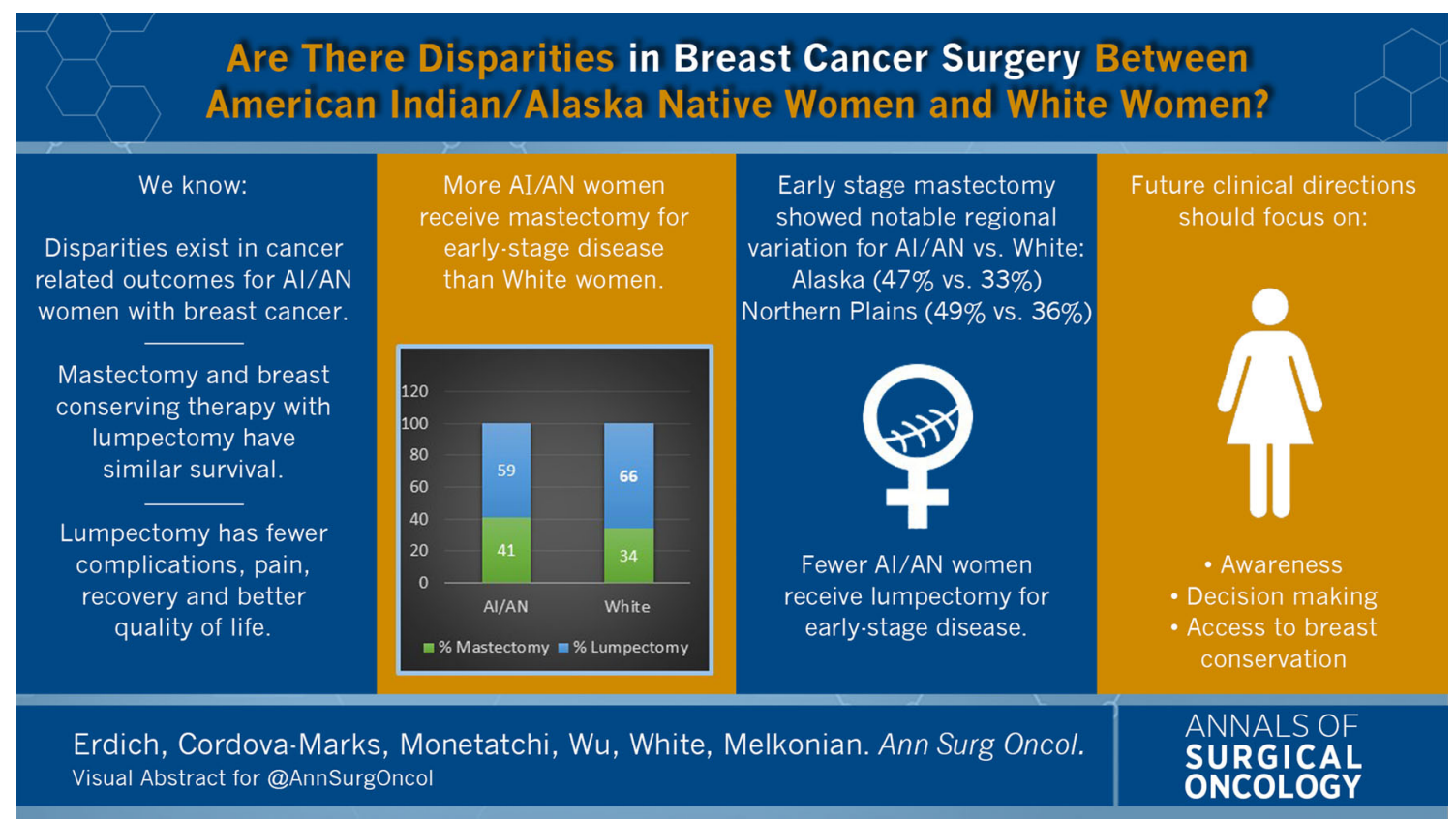

(C) Society of Surgical Oncology 2021

Published Online: 16 September 2021

J. Erdrich, MD MPH FACS

e-mail: jerdrich@surgery.arizona.edu
DISCLOSURE No conflicts of interest to disclose.

Publisher's Note Springer Nature remains neutral with regard to jurisdictional claims in published maps and institutional affiliations. 